\title{
IN VITRO POTENCY AND TOXICITY OF STREPTOMYCES SP. FERMENTATION PRODUCT AS AN ANTIMALARIAL THERAPY AGAINST PLASMODIUM FALCIPARUM
}

\author{
YUNI SETYANINGSIH ${ }^{1}$, ABDUL LATIF ${ }^{2}$, HENDRI ASTUTY ${ }^{3}$, DIN SYAFRUDDIN ${ }^{4}$, PUJI BUDI SETIA ASIH ${ }^{4 *}$
}

${ }^{1}$ Department of Biomedical Science, Faculty of Medicine, Universitas Indonesia, Jakarta, Indonesia. ${ }^{2}$ Agency for the Assessment and Application of Technology, Indonesian Institute of Sciences, Jakarta, Indonesia. ${ }^{3}$ Department of Parasitology, Faculty of Medicine, Universitas Indonesia, Jakarta, Indonesia. ${ }^{4}$ Malaria and Vector Resistance Unit, Eijkman Institute for Molecular Biology, Dr. Cipto Mangunkusumo National General Hospital, Jakarta, Indonesia. Email: puji@eijkman.go.id

Received 30 September 2018, Revised and Accepted 27 February 2019

\section{ABSTRACT}

Objective: This research aims to study the activity of a Streptomyces sp. fermentation product as an antimalarial modality in HepG2 cells.

Methods: The effects of the product against Plasmodium falciparum 3D7 were examined using an in vitro technique parasite. The potency of the Streptomyces sp. fermentation product was examined by determining the half maximal inhibitory concentration ( $\left.\mathrm{IC}_{50}\right)$, and the mechanism was studied using transmission electron microscopy (TEM). Toxicity tests were also conducted.

Results: The Streptomyces sp. fermentation product had an $\mathrm{IC}_{50}$ of $0.001 \mu \mathrm{g} / \mathrm{ml}$ against the parasite, versus values of 0.054 and $0.022 \mu \mathrm{g} / \mathrm{ml}$ for quinidine and prodigiosin, respectively. TEM revealed no formation of hemozoin. The Streptomyces sp. fermentation product was non-toxic in HepG2 cells based on its cytotoxicity concentration $50 \%$ of $1.380 \mu \mathrm{g} / \mathrm{ml}$.

Conclusion: The Streptomyces sp. fermentation product has potential as a potent and non-toxic antimalarial therapy.

Keywords: Antimalarial, Streptomyces sp. Fermentation Product, Half maximal inhibitory concentration, Transmission electron microscopy, Toxicity. (C) 2019 The Authors. Published by Innovare Academic Sciences Pvt Ltd. This is an open access article under the CC BY license (http://creativecommons. org/licenses/by/4. 0/) DOI: http://dx.doi.org/10.22159/ijap.2019.v11s1.16

\section{INTRODUCTION}

Malaria remains a global health problem, particularly in tropical areas [1]. According to Indonesia's Ministry of Health, the incidence of malaria declined between 2011 and 2015 from 1.75 per population to 0.85 per population [2]. However, the emergence of antimalarial drug resistance has threatened the goal of eradicating malaria [3]. The resistance of Plasmodium falciparum to artemisinin has been detected in five countries in the Greater Mekong Subregion [4].

Some drugs used to treat malaria are obtained from plants, such as quinine and artemisinin. Quinine was initially isolated from the bark of the Cinchona tree [4]. Artemisinin was developed from the Chinese herb Artemisia апnиа (qinghao) [5]. Other plant-based substances with potent antimalarial effects include the alcoholic extract of the root bark of Uapaca nitida (Euphorbiaceae) in Tanzania and extracts from Hernandia voyroni (Hernandiaceae) in Madagascar [6]. Research in Iran found that extracts from Buxus hyrcana, Erodium oxyrrhnchum, Glycyrrhiza glabra, and Ferula oopoda had significant antimalarial activity [7].

Studies have also identified potent antimalarial effects for the fermentation products of bacteria. Among them, Baba et al. described the antimalarial activity of the fermentation product of the endophytic bacterium Streptomyces SUK10 [8]. Boonlarppradab et al. revealed that the fermentation products of Saccharopolyspora A and B had antimalarial activity with half maximal inhibitory concentration $\left(\mathrm{IC}_{50}\right)$ of 4.1 and $3.9 \mu \mathrm{M}$, respectively [9].

Meanwhile, Streptomyces spp. has been widely studied for their antibiotic, antifungal, and anticancer activities [10]. Among these, S. griseous was the first species to be used in the industrial production of antibiotics [11]. In addition, research on the antimalarial effects of Streptomyces spp. has also been conducted. Isaka et al. reported that Streptomyces spectabilis isolated from soil samples in Thailand exhibited antimalarial activity against $P$. falciparum K1 [12]. Streptomyces spp. can produce various secondary metabolites $[13,14]$. For example, Streptomyces spp. from the ocean can produce the secondary metabolite prodigiosin, which has confirmed antimalarial effects $[15,16]$.

Thealkaloid prodigiosinis amember of theprodigininefamily, which has been reported to have antibacterial, antifungal, antimalarial, and antiprotozoal activity [17]. Papireddy et al. studied prodigiosin, undecylprodigiosin, and metacycloprodiginin, finding that all three had potent antimalarial activity, with $\mathrm{IC}_{50}$ of 8.0, 7.7, and $1.7 \mathrm{nM}$, respectively [18]. Lazaro et al. reported that heptyl prodigiosin displayed antimalarial activity in vitro [19]. Rahul et al. observed that prodigiosin inhibited the formation of Trypanosoma brucei gambiense, with an $\mathrm{IC}_{50}$ of $0.158 \pm 0.019 \mathrm{~g} / \mathrm{ml}$, and exerted antimalarial activity with an $\mathrm{IC}_{50}$ of $1.1 \pm 5.9 \mathrm{pg} / \mathrm{ml}$ in vitro [20]. The spectrum of the antifungal activity of prodigiosin is believed to be comprehensive, including species of Candida, Aspergillus, Penicillium, Saccharomyces, Cryptococcus, and Histoplasma [21]. Prodigiosin reportedly has a mechanism of action similar to quinine, namely, inhibiting the formation of hemozoin, which can be examined through transmission electron microscopy (TEM). TEM is useful in analyzing nearly all cellular components, including the cytoskeleton, membrane systems, and organelles [22,23].

Meanwhile, a compound or extract should be tested for toxicity to assess its potential harm to living things. Most drugs are metabolized in the liver, making HepG2 cells a suitable model to examine their metabolism. Therefore, this study used HepG2 cells to assess the efficacy, mechanism of action, and potential toxicity of a Streptomyces sp. fermentation product against the malaria-causing parasite $P$. falciparum.

\section{METHODS}

\section{Parasite}

This study used the P. falciparum 3D7 strain originating from the University of Tokyo that is propagated regularly at the Eijkman Institute 
for Molecular Biology. P. falciparum cells were thawed from liquid nitrogen using $\mathrm{NaCl}$ and 20\% RPMI complete medium. P. falciparum 3D7 cells were propagated in 10\% RPMI complete medium, with medium replacement every 2 days. Parasitemia was assessed using thin blood smears with Giemsa staining. Cultures of $P$. falciparum 3D7 that caused $2 \%$ parasitemia were used to determine $\mathrm{IC}_{50}$.

\section{Drug}

The fermentation product of Streptomyces spp. was obtained from LIPI. As controls, quinidine and prodigiosin were obtained from the Laboratory of Pharmacology, University of Indonesia.

\section{Viability testing}

Viability testing was performed using a 96-well plate, with cultures of $P$. falciparum at a volume of $180 \mathrm{ml}$ included in each well. A $20-\mathrm{ml}$ stock sample of the Streptomyces sp. fermentation product was added to well \#12 and then homogenized. A sample was taken from this well, introduced into well \#11, and homogenized, and this process was repeated until well \#4 were reached. The dilution method was also performed for the quinidine and prodigiosin stocks. The plate was incubated in a candle jar at $37{ }^{\circ} \mathrm{C}$ for $48 \mathrm{~h}$. Parasitemia was assessed by making a thin blood smear stained with $10 \%$ Giemsa solution and counted under a microscope. A curve of $\mathrm{IC}_{50}$ values was then created using the results between the test concentration and the percentage of growing parasites.

\section{TEM}

P. falciparum 3D7 was incubated with the fermentation products of Streptomyces spp. at the $\mathrm{IC}_{50}$ concentration, and untreated controls were incubated in a candle jar at $37^{\circ} \mathrm{C}$ for $48 \mathrm{~h}$. The samples were then diluted with a solution of $2.5 \%$ glutaraldehyde (in $0.1 \mathrm{M}$ cacodylate buffer $+3 \%$ sucrose) and incubated with shaking for $48 \mathrm{~h}$ at $4{ }^{\circ} \mathrm{C}$. The samples were then washed with $0.1 \mathrm{M}$ cacodylate buffer $+3 \%$ sucrose 3 times. The obtained pellets were incubated in a solution of $2 \%$ osmium tetraoxide $+2.5 \% \mathrm{~K}_{3} \mathrm{Fe}(\mathrm{CN})$ and washed 3 times with $0.1 \mathrm{M}$ cacodylate buffer $+3 \%$ sucrose. The pellets were then dissolved in $10 \%, 30 \%$, $50 \%, 70 \%, 95 \%$, or $100 \%$ ethanol. Pellets were then incubated with pure propylene oxide at room temperature for $1 \mathrm{~h}$ and centrifuged.

Pellets were then incubated with Spurr's resin (1:1) at room temperature for $30 \mathrm{~min}$ and then centrifuged, after which half of the supernatant was incubated for $30 \mathrm{~min}$ at room temperature and centrifuged. The supernatant was then removed, and the pellet was incubated in Spurr's resin overnight under vacuum. Samples were transferred to new tubes. Spurr's pure resin was introduced into each sample, which was incubated under vacuum at $70^{\circ} \mathrm{C}$ overnight. Parasite cells were stained using uranium salts.

\section{Toxicity test}

HepG2 cell cultures were taken from an $-80{ }^{\circ} \mathrm{C}$ freezer and thawed. The cell suspensions were then introduced into $15-\mathrm{ml}$ Falcon tubes; Dulbecco's Modified Eagle's medium (DMEM) complete medium (DMEM $+1 \%$ penicillin-streptomycin $+10 \%$ fetal bovine serum) was added, and the tubes were centrifuged at $500 \mathrm{rpm}$ for $10 \mathrm{~min}$. For each tube, the supernatant was discarded, complete medium was added, and the $20-\mathrm{ml}$ sample was placed in $75-\mathrm{cm}^{2}$ culture flasks. The cultures were incubated at $37^{\circ} \mathrm{C}$ in a $5 \% \mathrm{CO}_{2}$ atmosphere, and the medium was replaced every 2-3 days. Cells were harvested after approaching confluence. Cells were washed with PBS and incubated in $3 \mathrm{ml}$ of $0.25 \%$ trypsin in the incubator for $15 \mathrm{~min}$. Then, complete medium was added, and cells were centrifuged at $500 \mathrm{rpm}$ for $10 \mathrm{~min}$. The supernatant was discarded, $1 \mathrm{ml}$ of complete medium was added, and the number of cells was counted using a hemocytometer. HepG2 cells were cultured in 24-well plates at a density of $1 \times 10^{5}$ cells per well. After incubation for $24 \mathrm{~h}$, cells were exposed to various concentrations of the Streptomyces sp. fermentation product and incubated for 24 h. The cells were subsequently washed with PBS and incubated in $0.25 \%$ trypsin for $15 \mathrm{~min}$, after which cells were incubated in complete medium. The cell suspension was then centrifuged at $500 \mathrm{rpm}$ for 10 min. The supernatant was discarded, and cells were incubated in $1 \mathrm{ml}$ of PBS. Next, $10 \mathrm{ml}$ of the cell suspension was added to $10 \mathrm{ml}$ of Trypan blue and then homogenized. Then, $10 \mathrm{ml}$ of this mixture was placed in a hemocytometer chamber, and cell viability was calculated. This method was also performed for quinidine. The results of cell viability were used to determine the cytotoxicity concentration $50 \%\left(\mathrm{CC}_{50}\right)$.

\section{RESULTS}

\section{Cell Viability}

The inhibitory effects of the Streptomyces sp. fermentation product on the growth of P. falciparum 3D7 were examined in comparison to those of quinidine and prodigiosin. The $\mathrm{IC}_{50}$ of the fermentation product of Streptomyces spp. was $0.001 \mu \mathrm{g} / \mathrm{ml}$ (Table 1 and Fig. 1).

Conversely, the $\mathrm{IC}_{50}$ for quinidine was $0.054 \mu \mathrm{g} / \mathrm{ml}$ (Table 2 and Fig. 2). In addition, the $\mathrm{IC}_{50}$ for prodigiosin was $0.022 \mu \mathrm{g} / \mathrm{ml}$ (Table 3 and Fig. 3).

\section{TEM analysis of the fermentation product of Streptomyces spp.}

The morphology of parasites was examined using TEM at $\times 8000$ (Fig. 4). In the absence of treatment, the parasite grew normally with firm borders and healthy organelles, and hemozoin was produced.

Table 1: Inhibitory effects of the Streptomyces sp. fermentation product on $P$. falciparum 3D7 growth

\begin{tabular}{lll}
\hline Concentration $(\boldsymbol{\mu g} / \mathbf{m l})$ & Parasitemia $(\%)$ & Parasite growth $(\%)$ \\
\hline No treatment & 3.1 & 100.0 \\
$10^{-3}$ & 1.7 & 54.3 \\
$10^{-2}$ & 1.3 & 40.4 \\
$10^{-1}$ & 0.7 & 21.3 \\
1 & 1.1 & 34.0 \\
10 & 0.9 & 29.8 \\
$10^{2}$ & 0.5 & 16.0 \\
$10^{3}$ & 0.0 & 0.0 \\
$10^{4}$ & 0.0 & 0.0 \\
$10^{5}$ & 0.0 & 0.0 \\
\hline
\end{tabular}

P. falciparum: Plasmodium falciparum

Table 2: Growth of P. falciparum 3D7 following exposure to quinidine

\begin{tabular}{lll}
\hline Concentration $(\boldsymbol{\mu g} / \mathbf{m l})$ & Parasitemia $(\%)$ & Parasite growth $(\%)$ \\
\hline No treatment & 2.38 & 100.0 \\
$5 \times 10^{-5}$ & 2.13 & 89.5 \\
$5 \times 10^{-4}$ & 2.62 & 110.3 \\
$5 \times 10^{-3}$ & 1.92 & 80.6 \\
$5 \times 10^{-2}$ & 0.59 & 24.8 \\
$5 \times 10^{-1}$ & 0.64 & 26.9 \\
5 & 0.47 & 19.8 \\
50 & 0.16 & 6.5 \\
$5 \times 10^{2}$ & 0.00 & 0.0 \\
$5 \times 10^{3}$ & 0.00 & 0.0 \\
\hline
\end{tabular}

P. falciparum: Plasmodium falciparum

Table 3: Growth of P. falciparum 3D7 following exposure to prodigiosin

\begin{tabular}{lll}
\hline Concentration $(\boldsymbol{\mu g} / \mathbf{m l})$ & Parasitemia $(\%)$ & Parasite growth $(\%)$ \\
\hline No treatment & 4.69 & 100.0 \\
$10^{-7}$ & 6.34 & 135.3 \\
$10^{-6}$ & 5.87 & 125.3 \\
$10^{-5}$ & 5.48 & 116.9 \\
$10^{-4}$ & 5.04 & 107.5 \\
$10^{-3}$ & 5.22 & 111.4 \\
$10^{-2}$ & 3.29 & 70.2 \\
$10^{-1}$ & 0.59 & 12.5 \\
1 & 0.00 & 0.0 \\
10 & 0.00 & 0.0 \\
\hline
\end{tabular}

P. falciparum: Plasmodium falciparum 


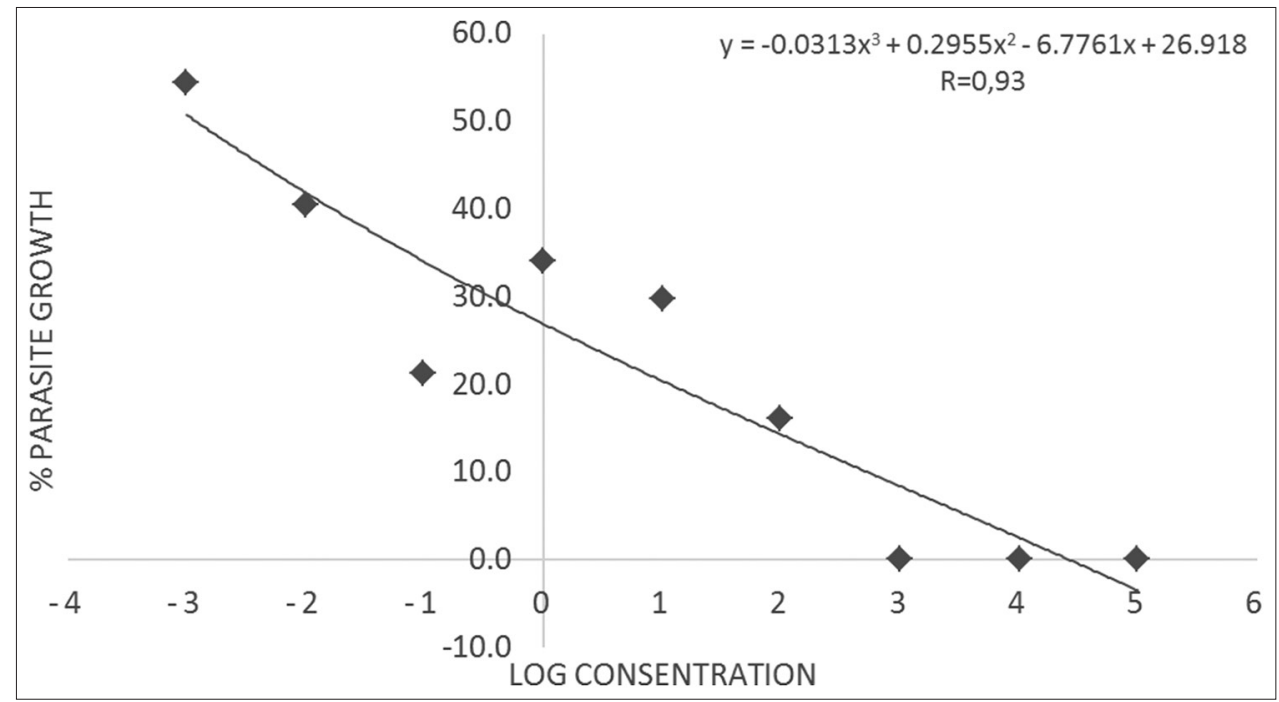

Fig. 1: The growth curve of Plasmodium falciparum 3D7 following exposure to the Streptomyces sp. fermentation product

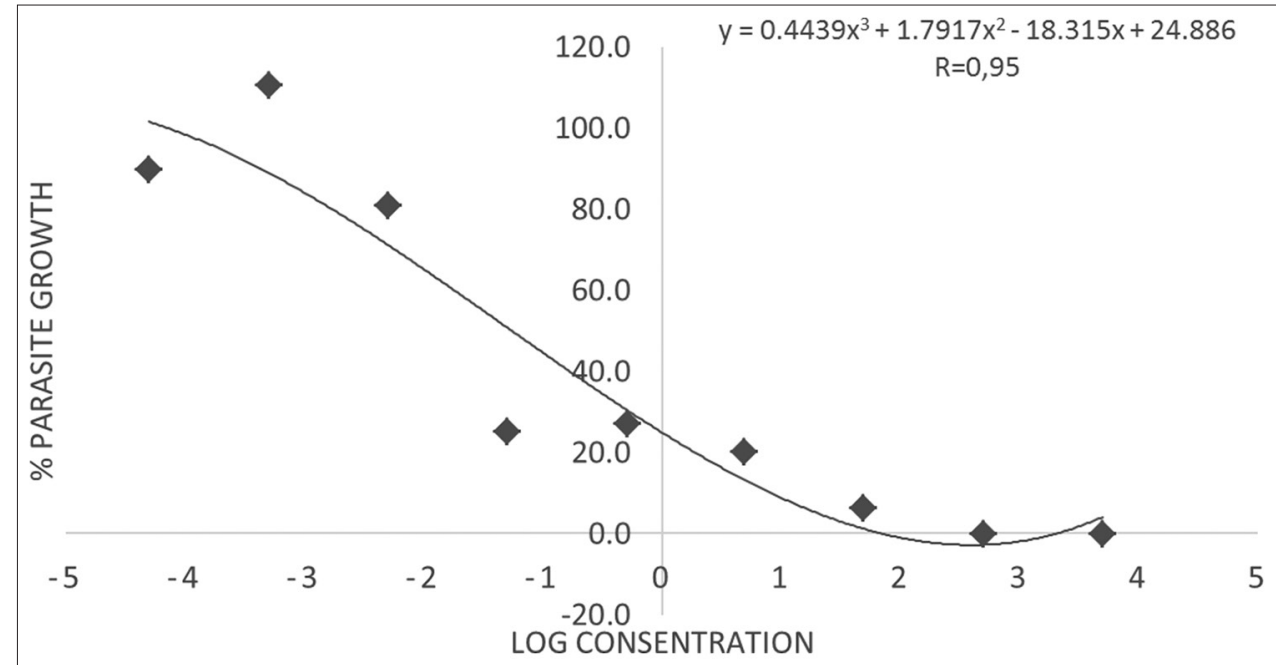

Fig. 2: The growth curve of Plasmodium falciparum 3D7 following exposure to quinidine

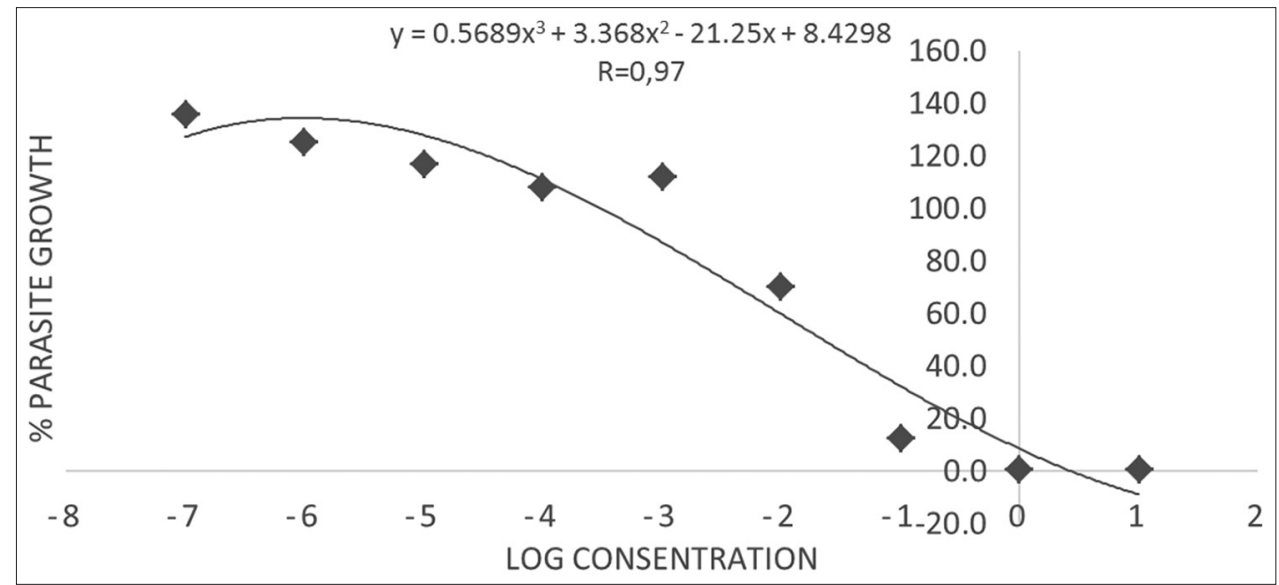

Fig. 3: The growth curve of Plasmodium falciparum 3D7 following exposure to prodigiosin

Conversely, when the parasite was exposed to the fermentation product of Streptomyces spp., hemozoin was not produced.

Toxicity of the fermentation product of Streptomyces spp. in HepG2 cells was evaluated.
The toxicity of the fermentation product of Streptomyces spp. in HepG2 cells was evaluated using Trypan blue staining. Then, a $\mathrm{CC}_{50}$ curve for the fermentation product of Streptomyces spp. relative to the untreated controls was created. The toxicity of quinidine was similarly examined. At concentrations $\leq 100 \mathrm{pg} / \mathrm{ml}$, the Streptomyces sp. fermentation 
product did not induce significant cytotoxicity (Table 4). Following exposure to higher concentrations, the $\mathrm{CC}_{50}$ of the fermentation product was calculated as $1.380 \mu \mathrm{g} / \mathrm{ml}$ (Fig. 5).

Conversely, quinidine at a concentration of $200 \mu \mathrm{g} / \mathrm{ml}$ was completely cytotoxic to HepG2 cells, whereas cell viability exceeded 50\% for smaller concentrations (Table 5). After calculating the cell viability curve, the $\mathrm{CC}_{50}$ was determined as $160 \mathrm{pg} / \mathrm{ml}$ (Fig. 6).

\section{DISCUSSION}

Natural products have long been investigated in drug discovery, included antimalarial drugs. $45 \%$ of clinically used antimalarial drugs

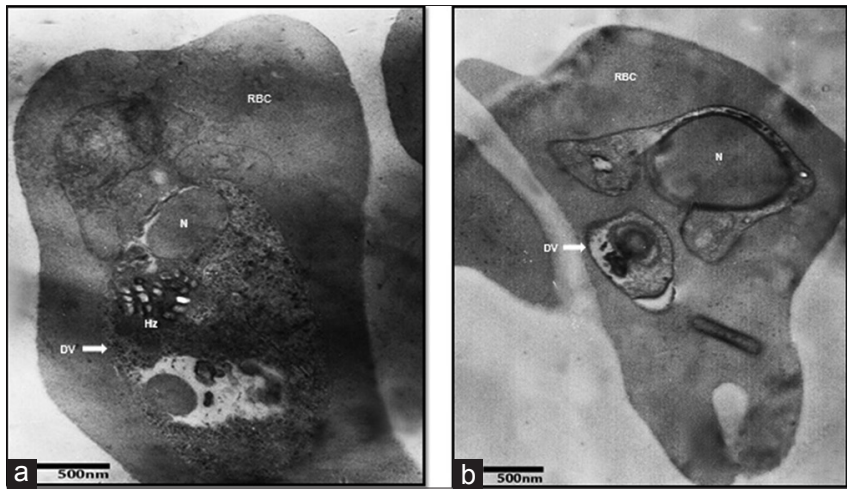

Fig. 4: Morphology of Plasmodium falciparum 3D7 assessed through transmission electron microscopy at $\times \mathbf{8 0 0 0}$

magnification. (a) In the absence of treatment, hemozoin was produced. (b) Hemozoin was not produced when the parasite was exposed to the fermentation product of Streptomyces spp.

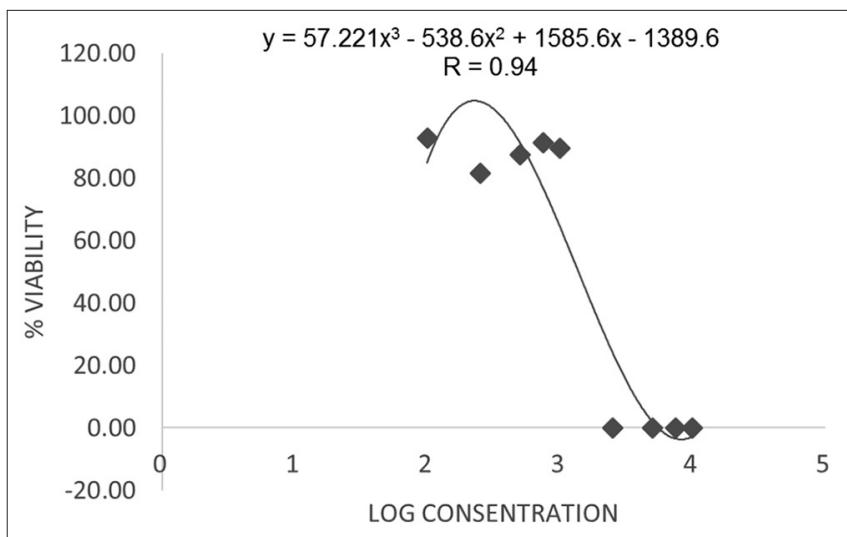

Fig. 5: The cell viability curve following exposure to the Streptomyces sp. fermentation product

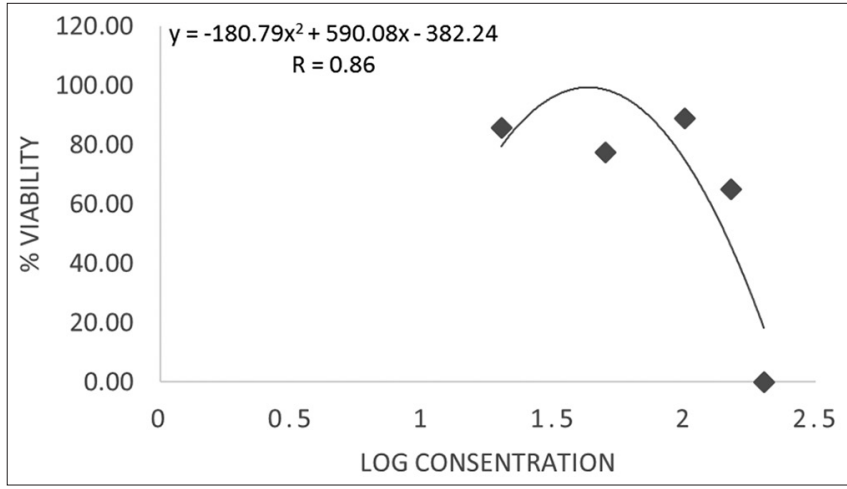

Fig. 6: Cell viability curve following quinidine exposure were derived from natural products [24]. An example is the first antimalarial drug, quinine, which was isolated from the bark of the Cinchona spp. (Rubiaceae) [6]. In 1972, a group of Chinese researchers isolated the antimalarial drug artemisinin from the traditional Chinese herb A. апnиa (Asteraceae) [25]. In addition, Actinomycetes bacteria also produce a wide range of bioactive compounds, some of which have antimalarial effects [24].

In prior research using $S$. spectabilis BCC 4785 isolated from soil samples, the metabolite metacycloprodigiosin was found to have antimalarial activity. Prodigiosin is a secondary metabolite produced by Streptomyces and Serratia spp. The Streptomyces sp. fermentation product supposedly contains prodigiosin, a secondary metabolite, and alkaloid [26]; thus, it might have the same mechanism of action as the alkaloids quinine and quinidine. In another study, Lazaro et al. found that heptyl prodigiosin has activity similar to quinine against sensitive Plasmodium 3D7 [19].

In a previous study, Intaraudom et al., using a crude extract of Streptomyces sp. BCC27095 isolated from soil samples in Thailand, reported an $\mathrm{IC}_{50}$ of $2.72 \mu \mathrm{g} / \mathrm{ml}$ against a multidrug-resistant $P$. falciparum K-1 strain [27]. Another study using crude extracts of Streptomyces sp. BCC26924 reported an $\mathrm{IC}_{50}$ of $0.77 \mu \mathrm{g} / \mathrm{ml}$ against the same strain [28]. Meanwhile, Rakotondraibe et al. recorded IC ${ }_{50}$ of $2.5-10 \mu \mathrm{g} / \mathrm{ml}$ for extracts of Streptomyces spp. against P. falciparum Dd2 strains [24]. These results illustrate that the fermentation product of Streptomyces spp. has good antimalarial activity. However, it must be noted that this study used drug-resistant strains, whereas prior research used drugresistant Plasmodium spp.

In this study, the fermentation product of Streptomyces spp. appeared to have stronger antimalarial activity than the control agents, possibly because it contains several secondary metabolites with antimalarial effects. Meanwhile, the controls were only single agents. Therefore, further research is needed to more closely identify the antimalarial agents.

P. falciparum degrades hemoglobin to acquire nutrients for growth. This results in increased heme levels, which are toxic to the parasite. To overcome this toxicity, the parasite polymerizes heme into hemozoin, which is nontoxic. In this study, it appears that hemozoin was not formed following exposure to the Streptomyces sp. fermentation product, resulting in heme accumulation and death of the parasite.

Table 4: Cell viability following exposure to the fermentation product of Streptomyces spp

\begin{tabular}{ll}
\hline Concentration $(\boldsymbol{\mu g} / \mathbf{m l})$ & \% viability \\
\hline No treatment & 100 \\
100 & 92.90 \\
250 & 81.42 \\
500 & 87.43 \\
750 & 91.26 \\
1000 & 89.62 \\
2500 & 0.00 \\
5000 & 0.00 \\
7500 & 0.00 \\
10,000 & 0.00 \\
\hline
\end{tabular}

Table 5: Cell viability following quinidine exposure

\begin{tabular}{ll}
\hline Concentration $(\boldsymbol{\mu g} / \mathrm{ml})$ & \% viability \\
\hline No treatment & 100.00 \\
20 & 85.56 \\
50 & 77.22 \\
100 & 88.89 \\
150 & 65.00 \\
200 & 0.00 \\
\hline
\end{tabular}


Herbs are used as medicines in developing countries based on the presence of secondary metabolites [29]. Bacteria such as Streptomyces spp. also produce secondary metabolites, and thus, toxicology testing is needed to ensure the safe use of fermentation products. The current analysis using HepG2 cells indicated that the fermentation product should be nontoxic in comparison to the controls.

\section{CONCLUSION}

The fermentation product of Streptomyces sp. exhibited potency as an antimalarial agent, with an $\mathrm{IC}_{50}$ value of $0.001 \mu \mathrm{g} / \mathrm{ml}$. The $\mathrm{CC}_{50}$ of the fermentation product in HepG2 cells was $1380 \mu \mathrm{g} / \mathrm{ml}$. The test results indicate that the Streptomyces sp. fermentation product exerts strong antimalarial effects without causing toxicity, although additional research is needed to verify these findings.

\section{REFERENCES}

1. Cui L, Mharakurwa S, Ndiaye D, Rathod PK, Rosenthal PJ. Antimalarial drug resistance: Literature review and activities and findings of the ICEMR network. Am J Trop Med Hyg 2015;93:57-68.

2. Indonesian Ministry of Health. Control of Drug and Insecticide Resistance. Malaria Management Guidelines; 2014. p. 129-38.

3. World Health Organization. WHO Global Malaria Programme. World Malaria Report 2015. Available from: https://www.apps.who. int/iris/bitstream/handle/10665/200018/9789241565158_eng.pdf; jsessionid $=5859 \mathrm{DB} 1 \mathrm{FF} 50 \mathrm{D} 46 \mathrm{~B} 863 \mathrm{C} 585 \mathrm{~A} 70 \mathrm{~A} 6 \mathrm{DCE} 13$ ? sequence $=1$. [Last accessed on 2016 Jan 28].

4. Petersen I, Eastman R, Lanzer M. Drug-resistant malaria: Molecular mechanisms and implications for public health. FEBS Lett 2011;585:1551-62.

5. Meshnick SR. Artemisinin: Mechanisms of action, resistance and toxicity. Int J Parasitol 2002;32:1655-60.

6. Saxena S, Pant N, Jain DC, Bhakuni RS. Antimalarial agents from plant sources. Curr Sci 2003;85:1314-29.

7. Mojab F. Antimalarial natural products: A review. Avicenna J Phytomed 2012;2:52-62

8. Baba MS, Zin NM, Hassan ZA, Latip J, Pethick F, Hunter IS, et al. In vivo antimalarial activity of the endophytic actinobacteria, streptomyces SUK 10. J Microbiol 2015;53:847-55

9. Boonlarppradab C, Suriyachadkun C, Rachtawee P, Choowong W. Saccharosporones A, B and C, cytotoxic antimalarial angucyclinones from Saccharopolyspora Sp. BCC 21906. J Antibiot (Tokyo) 2013;66:305-9.

10. Bérdy J. Bioactive microbial metabolites. J Antibiot (Tokyo) 2005; 58:1-26.

11. Procópio RE, Silva IR, Martins MK, Azevedo JL, Araújo JM. Antibiotics produced by streptomyces. Braz J Infect Dis 2012;16:466-71.

12. Isaka M, Jaturapat A, Kramyu J, Tanticharoen M, Thebtaranonth Y. Potent in vitro antimalarial activity of metacycloprodigiosin isolated from Streptomyces spectabilis BCC 4785. Antimicrob Agents
Chemother 2002;46:1112-3.

13. Manteca A, Sanchez J. Streptomyces development in colonies and soils. Appl Environ Microbiol 2009;75:2920-4

14. Bibb MJ. Regulation of secondary metabolism in streptomycetes. Curr Opin Microbiol 2005;8:208-15

15. El-bondkly AM. Overproduction and biological activity of prodigiosinlike pigments from recombinant fusant of endophytic marine Streptomyces species. Antonie van Leeuwenhoek 2012;102:719-34.

16. Soliev AB, Hosokawa K, Enomoto K. Bioactive pigments from marine bacteria: Applications and physiological roles. Evid Based Complement Alternat Med 2011;2011:670349.

17. Lins LJ, Maciel CC, Xavier HS, da Silva CA, Campos-Takaki GM. Production and toxicological evaluation of prodigiosin from Serratia marcescens UCP/WFCC1549 on mannitol solid medium. Int J Appl Res Nat Prod 2014;7:32-8.

18. Papireddy K, Smilkstein M, Kelly JX, Shweta, Salem SM, Alhamadsheh $\mathrm{M}$, et al. Antimalarial activity of natural and synthetic prodiginines. J Med Chem 2011;54:5296-306.

19. Lazaro JE, Nitcheu J, Predicala RZ, Mangalindan GC, Nesslany F, Marzin D, et al. Heptyl prodigiosin, a bacterial metabolite, is antimalarial in vivo and non-mutagenic in vitro. J Nat Toxins 2002;11:367-77.

20. Rahul S, Chandrashekhar P, Hemant B, Bipinchandra S, Mouray E, Grellier $\mathrm{P}$, et al. In vitro antiparasitic activity of microbial pigments and their combination with phytosynthesized metal nanoparticles. Parasitol Int 2015;64:353-6.

21. Stankovic N, Senerovic L, Ilic-Tomic T, Vasiljevic B, NikodinovicRunic J. Properties and applications of undecylprodigiosin and other bacterial prodigiosins. Appl Microbiol Biotechnol 2014;98:3841-58.

22. Winey M, Meehl JB, O'Toole ET, Giddings TH Jr. Conventional transmission electron microscopy. Mol Biol Cell 2014;25:319-23.

23. Wilkening S, Stahl F, Bader A. Comparison of primary human hepatocytes and hepatoma cell line hepg2 with regard to their biotransformation properties. Drug Metab Dispos 2003;31:1035-42.

24. Rakotondraibe LH, Rasolomampianina R, Park HY, Li J, Slebodnik C, Brodie PJ, et al. Antiproliferative and antiplasmodial compounds from selected Streptomyces species. Bioorg Med Chem Lett 2015;25:5646-9.

25. Chaturvedi D, Goswami A, Saikia PP, Barua NC, Rao PG. Artemisinin and its derivatives: A novel class of anti-malarial and anti-cancer agents. Chem Soc Rev 2010;39:435-54

26. de Araújo HW, Fukushima K, Takaki GM. Prodigiosin production by Serratia marcescens UCP 1549 using renewable-resources as a low cost substrate. Molecules 2010;15:6931-40.

27. Intaraudom C, Bunbamrung N, Dramae A, Danwisetkanjana K, Rachtawee P, Pittayakhajonwut P. Antimalarial and antimycobacterial agents from Streptomyces Sp. Tetrahedron Lett 2015;56:6875-7.

28. Intaraudom C, Rachtawee P, Suvannakad R, Pittayakhajonwut P. Antimalarial and antituberculosis substances from Streptomyces Sp. BCC26924. Tetrahedron 2011;67:7593-7.

29. Boukandou Mounanga M, Mewono L, Aboughe Angone S. Toxicity studies of medicinal plants used in Sub-Saharan Africa. J Ethnopharmacol 2015;174:618-27. 